\title{
PRESERVACIÓN DIGITAL Y DIFUSIÓN DE LA REVISTA EDUCACIÓN Y BIBLIOTECA DESDE EL REPOSITORIO GREDOS DE LA UNIVERSIDAD DE SALAMANCA
}

\author{
José-Antonio Merlo-Vega y Tránsito Ferreras-Fernández
}
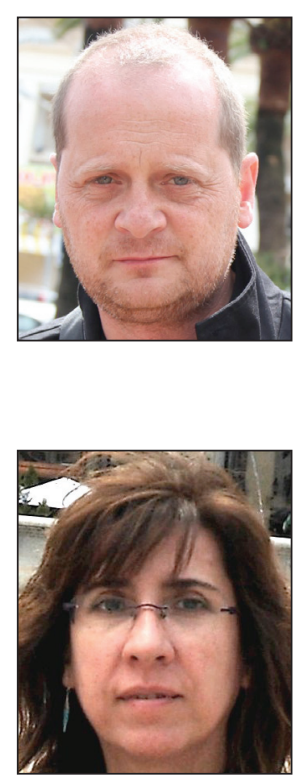

José-Antonio Merlo-Vega es doctor por la Universidad de Salamanca, donde dirige el Servicio de Bibliotecas. Es profesor del Departamento de Biblioteconomía y Documentación y coordinador del Grupo de Trabajo de Repositorios de Rebiun. En 2013 es investigador invitado de The University of North Carolina at Greensboro e investigador del Metadata Research Center de The University of North Carolina at Chapel Hill. Fue colaborador de Educación y biblioteca en diversas ocasiones dirigiendo especiales sobre tecnologías, web social, referencia o bibliotecas públicas. http://orcid.org/0000-0002-9102-4408

Univ. de Salamanca, Servicio de Bibliotecas Francisco de Vitoria, 6-16. 37007 Salamanca, España merlo@usal.es

Tránsito Ferreras-Fernández es licenciada en filología francesa y máster en sistemas de información digital por la Universidad de Salamanca (USAL). Pertenece al Cuerpo de Ayudantes de Archivos, Bibliotecas y Museos de la USAL. Es coordinadora técnica del repositorio institucional Gredos. Trabaja en la promoción del acceso abierto y la gestión y coordinación del repositorio. Estudia el impacto del acceso abierto, el desarrollo e implementación de esquemas de metadatos en DSpace y a la preservación digital. Participa en el grupo de trabajo Repositorios de Rebiun y en Europeana Network.

http://orcid.org/0000-0002-2766-5382
Univ. de Salamanca, Bca. Sta. María de los Ángeles Libreros, 68. 37008 Salamanca, España transiff@usal.es

\section{Resumen}

El repositorio Gredos de la Universidad de Salamanca ofrece en acceso abierto el contenido completo de la revista Educación y biblioteca. Se describen el origen y objetivos del proyecto de digitalización y depósito de la revista en el repositorio con el fin de preservar a largo plazo sus contenidos. Se explica la metodología y los procesos empleados. Gracias a la interoperabilidad del repositorio Gredos, es accesible a través de otros portales como Hispana, Europeana, OAlster/Worldcat y $B A S E$. Educación y biblioteca ha dejado de editarse, pero sus contenidos estarán disponibles de forma constante y abierta.

\section{Palabras clave}

Preservación digital, Publicaciones profesionales, Educación y biblioteca, Repositorios, Gredos.

Title: Digital preservation and distribution of the Educación y biblioteca journal by the University of Salamanca's Gredos repository

\section{Abstract}

Gredos, the institutional repository of Salamanca University, offers full-text open access to the Educación y biblioteca (Education and the library) journal. The origins and goals of the digitization project and of placing the journal in the repository are described, along with the methodology and processes used to carry out the project. This has ensured the journal's longterm preservation and dissemination of its contents. Owing to the interoperability of the Gredos repository, Educación $y$ biblioteca is available through portals including Hispana, Europeana, OAlster / WorldCat and BASE. Although the journal is no longer published, its content remains constantly available.

\section{Keywords}

Digital preservation, Professional publications, Educación y biblioteca, Repositories, Gredos.

Merlo-Vega, José-Antonio; Ferreras-Fernández, Tránsito (2013). “Preservación digital y difusión de la revista Educación y biblioteca desde el repositorio Gredos de la Universidad de Salamanca". El profesional de la información, marzo-abril, v. 22, n. 2, pp. 143-148.

http://dx.doi.org/10.3145/epi.2013.mar.08 


\section{Origen y objetivos del proyecto}

Educación y biblioteca, revista profesional especializada en bibliotecas públicas y escolares y en sus relaciones con la educación, comenzó a editarse en 1989 y cesó su actividad en 2011. Sus 22 años de trayectoria coinciden con los del desarrollo de la biblioteconomía como ciencia en España, visible en una sólida red de centros de formación, un colectivo de profesionales con perfiles específicos, una nómina significativa de investigadores y una amplia oferta de revistas científicas y de divulgación.

La edición de revistas especializadas en biblioteconomía estaba protagonizada en el momento de la aparición de Educación y biblioteca por publicaciones de asociaciones profesionales, a las que se unieron las editadas por departamentos universitarios. En ambos casos, los enfoques reproducían los modelos humanísticos de revistas en las que los contenidos se caracterizaban por ser de contribuciones afines a las entidades editoras.

\section{La USAL planteó a los titulares de la re-} vista el proyecto de preservación digital para su difusión en acceso abierto

La aparición de Educación y biblioteca se orienta claramente a reivindicar la función activa de la biblioteca en la educación. Para ello elige un modelo editorial alejado del de las revistas científicas y muy próximo al de las publicaciones culturales y de información general, dando importancia a notas de actualidad, a artículos de enfoque periodístico y a reseñas de recursos didácticos y profesionales. Desde sus inicios la revista quiso orientar sus contenidos a un lector profesional -bibliotecarios y educadores-, al que ofrecía mensual o bimestralmente esta información. A lo largo de más de dos décadas publicó 183 números y cerca de 2.500 contribuciones.

La revista fue una iniciativa editorial privada de la empresa Tilde Ediciones, en colaboración con la Asociación Educación y Biblioteca. Su modelo de negocio se basaba en la venta de la revista, las suscripciones y los ingresos por publicidad. A

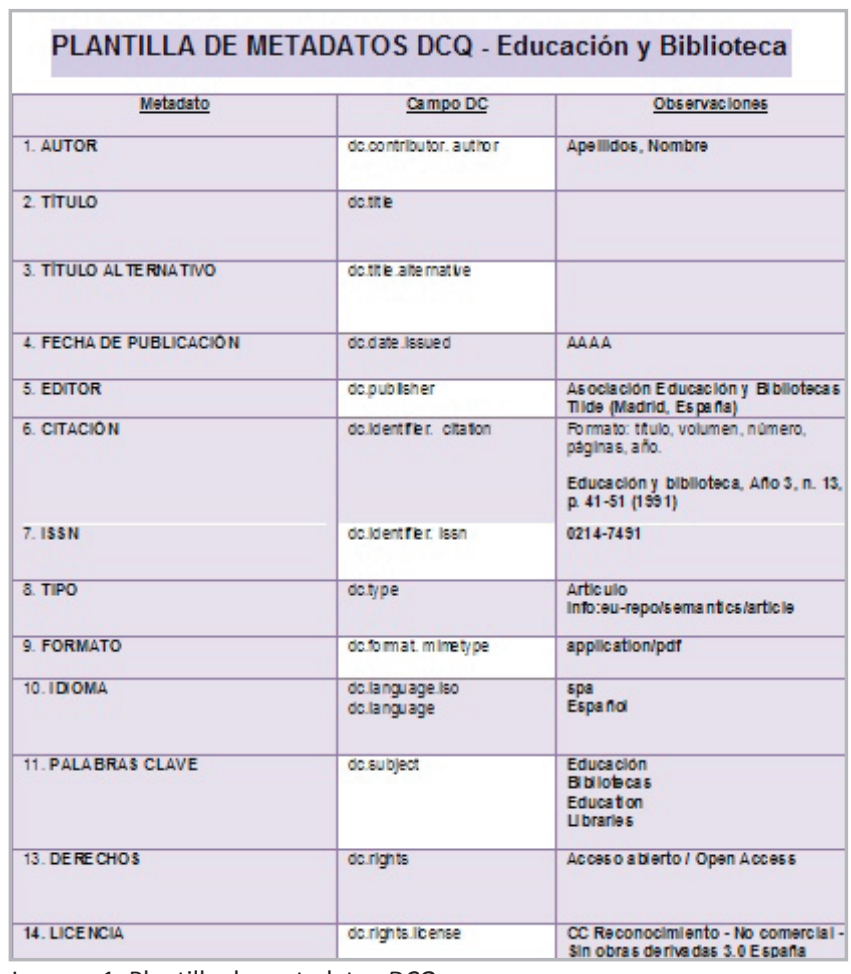

Imagen 1. Plantilla de metadatos $D C Q$

pesar de realizarse con un equipo reducido, su edición destacaba por su cuidada redacción y diseño. Cada número se enfocaba hacia un tema destacado, coordinado por un especialista de forma desinteresada, quien solicitaba las colaboraciones a otros especialistas del tema tratado. Además, el equipo de redacción se encargaba de cubrir noticias de actualidad, proponer reseñas de novedades a otros profesionales y, sobre todo, ofrecer sus páginas a bibliotecas y centros educativos para que expusieran sus experiencias. Los resultados han sido 22 años de difusión de contenidos en los que se constata la historia de una profesión y de la investigación vinculada a la misma. Gracias a Educación y biblioteca se puede conocer la evolución de la realidad bibliotecaria española, disponer de información de acontecimientos que sólo fueron reflejados en ella o constatar el estado de la investigación en los temas de referencia de la revista.

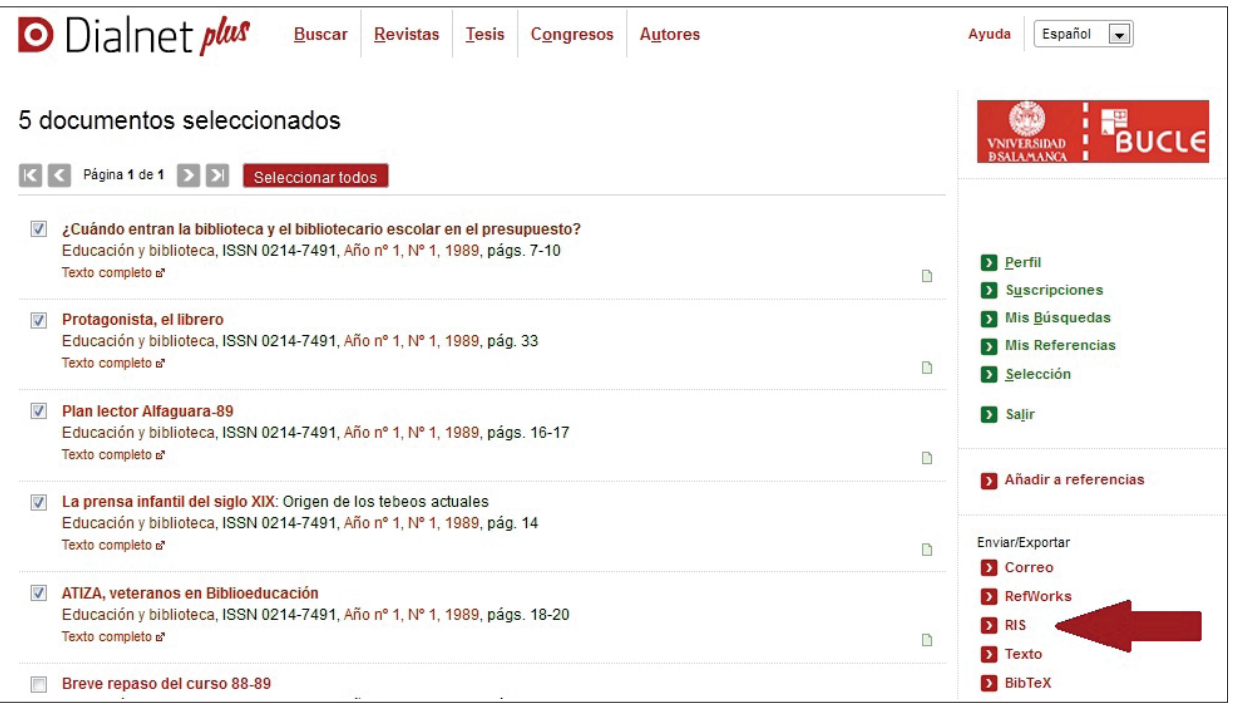

Imagen 2. Exportación en formato RIS desde Dialnet
El número 183, de mayo-junio de 2011, fue el último editado. La situación económica no permitía continuar la labor iniciada en 1989 y, aunque no se expresaba claramente en este último número, sus responsables ya lo habían comunicado a sus colaboradores. Se ponía fin a una productiva experiencia, que había aportado al colectivo bibliotecario una elevada bibliografía y un constante estado de la cuestión.

El hecho de que la revista siempre hubiese apostado por la edición impresa y de que la entidad responsable no pudie- 


\section{Ejemplo fichero .ris}

$$
\begin{aligned}
& \text { TY - JOUR } \\
& \text { AU - Mera Lamela, María Paz } \\
& \text { T1 - Lectura y bibliotecasescolares: Consellería de Cultura e Deportes } \\
& \text { JF - Educación y biblioteca } \\
& \text { PY - 1991/// } \\
& \text { VL - } 3 \\
& \text { IS - } 15 \\
& \text { SP - } 62 \\
& \text { SN - } 0214-7491 \\
& \text { N1 - Fecha de exportación: el } 24 \text { de octubre de } 2011 \\
& \text { N1 - Origen: DIALNET } \\
& \text { UR - http://dialnet.unirioja.es/servlet/extart?codigo=3251074 } \\
& \text { ER - }
\end{aligned}
$$

Imagen 3. Ejemplo de fichero RIS

ra hacerse cargo de un proyecto de preservación de los números publicados podría suponer que el trabajo realizado en más de dos décadas se convirtiera en material exclusivo de hemeroteca y se le privara de su merecida difusión. Por este motivo, la Universidad de Salamanca (USAL) planteó a los titulares de la revista la posibilidad de coordinar el proyecto de preservación digital para su difusión en acceso abierto. Ya había acometido proyectos similares con otras revistas externas, por lo que tenía experiencias previas, además de haber mantenido fluidos vínculos con la publicación. El contexto bibliotecario salmantino está presente periódicamente en la revista, que ha recogido experiencias y colaboraciones de sus centros formativos y profesionales.

La propuesta es recibida afirmativamente y durante el verano de 2011 se establecen los mecanismos para la puesta en marcha.

Las fuentes empleadas para la obtención de la colección completa son diversas:

- edición digital en cd-rom publicada en 2004 por Educación y biblioteca y la Junta de Comunidades de CastillaLa Mancha, en la que se recogían en formato pdf los números 1 a 141, correspondientes a los 15 primeros años (mayo 1989-mayo/junio 2004);

- archivos digitales disponibles en su versión maquetada para imprenta;

- ejemplares impresos para el escaneado directo de los números de los que no se disponía de versión digital.

El 16 de noviembre de 2011 se celebra en Madrid un homenaje a la revista, en el que se presenta la colección completa de Educación y biblioteca disponible en el repositorio documental Gredos de la USAL, gracias al convenio firmado entre Juana Abellán, titular de los derechos de la revista y la USAL.

La primera carga realizada correspondía a los números íntegros, que paulatinamente fueron describiéndose artículo por artículo e incorporándose al repositorio Gredos. En enero de 2013 ha finalizado la puesta

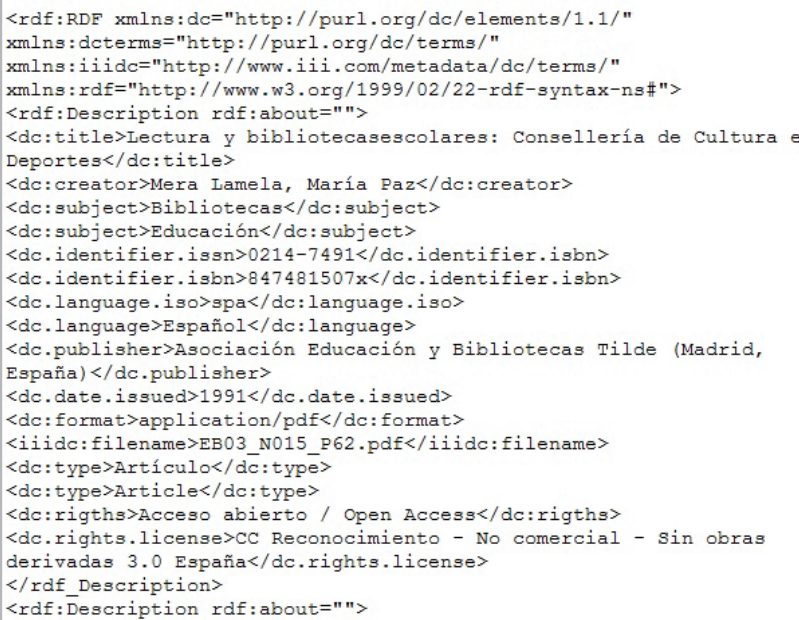

Imagen 4. Ejemplo de fichero RDF de un artículo de Educación y biblioteca

en acceso abierto de los artículos individuales, aunque se sigue trabajando en la revisión de las materias y en el control de autoridades. La colección final ofrecida es de 2.466 registros, correspondientes a contribuciones individuales, que se han agrupado en subcomunidades (años de publicación) y colecciones (números). Como se explica en este artículo, el repositorio Gredos se recolecta por servicios nacionales e internacionales, por lo que sus contenidos se pueden encontrar a través de buscadores académicos, grandes bibliotecas digitales y todos los recolectores nacionales e internacionales de ciencia abierta.

\section{Metodología y establecimiento de procedimientos}

El repositorio Gredos está construido y gestionado con software libre (DSpace), utiliza metadatos Dublin core cualificado $(D C Q)$ en las descripciones de los objetos digitales, cumple con el protocolo de archivos abiertos para la recolección de metadatos (OAI-PMH) y con el protocolo de archivos abiertos para la reutilización e intercambio de objetos (OAIORE). Sus contenidos se difunden bajo una licencia Creative commons 3.0 España.

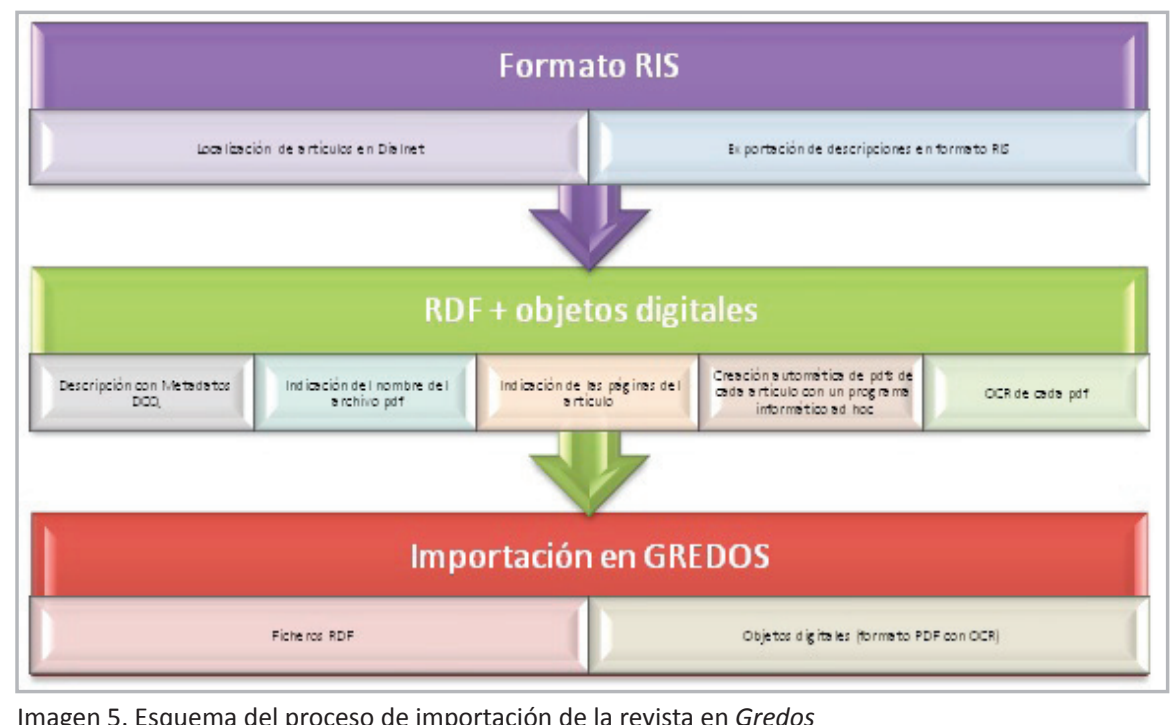

Imagen 5. Esquema del proceso de importación de la revista en Gredos 
Imágenes para difusión web

\begin{tabular}{|l|c|c|c|c|c|c|}
\hline Tipo de Imagen & Definición & Resolución & Tamaño & Formato & Compresión & Nomenclatura \\
\hline Soporte papel* & $\begin{array}{c}\text { Original color: Color, 24 bits } \\
\text { Original b/n: Escala de grises, 8 bits }\end{array}$ & $150 \mathrm{ppp}$ & $100 \% / 1: 1$ & JPEG o PDF & JPEG: Media & Seriada \\
\hline Negativo y diapositivas b/n & Escala de grises, 8 bits & $300 \mathrm{ppp}$ & $100 \% / 1: 1$ & JPEG o PDF & JPEG: Media & Seriada \\
\hline $\begin{array}{l}\text { Negativo y diapositivas } \\
\text { color }\end{array}$ & Color, 24 bits & $300 \mathrm{ppp}$ & $100 \% / 1: 1$ & JPEG o PDF & JPEG: Media & Seriada \\
\hline
\end{tabular}

Imagen 6. Parámetros de digitalización para la difusión de imágenes en la Web

El proyecto de integración de EyB en el repositorio fue dirigido por el Servicio de Bibliotecas de la USAL y para el mismo se diseñaron herramientas específicas desde el Servicio de Innovación y Producción Digital, responsable de las aplicaciones de los recursos en abierto (DSpace, OCW, OJS). Por un lado, se disponía de la descripción de la revista, casi al completo, en Dialnet. Se trataba de un vaciado de los artículos de cada uno de los números, de los que faltaban las descripciones correspondientes a los años 1989 a 1992, ambos inclusive. Éstas fueron realizadas por la USAL y se ofrecieron a Dialnet.

Los ficheros pdf, tanto los del citado cd-rom, como los facilitados por la editorial, estaban bloqueados, no eran legibles por OCR (optical character recognition) y no estaban divididos por artículos. El proceso de carga de la revista en el repositorio comprendió dos fases simultáneas, el tratamiento de la información (descripción con metadatos) y la creación y tratamiento de los objetos digitales.

\section{Descripción de los artículos}

Para la descripción de los artículos y contribuciones se estableció un flujo de trabajo que comprendía los siguientes pasos:

1. Estudio y análisis de la documentación: tipología documental del material (artículos y números completos de revista), e información (metadatos).

2. Creación de la plantilla de metadatos necesarios para la descripción en formato Dublin core cualificado (DCQ) (imagen 1).

3. Búsqueda y localización de los artículos descritos en Dialnet.

4. Exportación de la información de cada artículo desde

Archivo Institucional

7NMESTRSS Documentos de carácter institucional,
informativos, normativos o administrativos de

Repositorio Científico

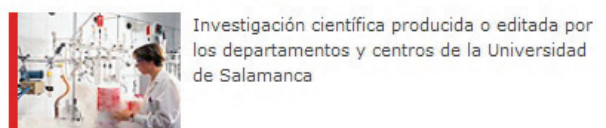

Imagen 7. Secciones de Gredos

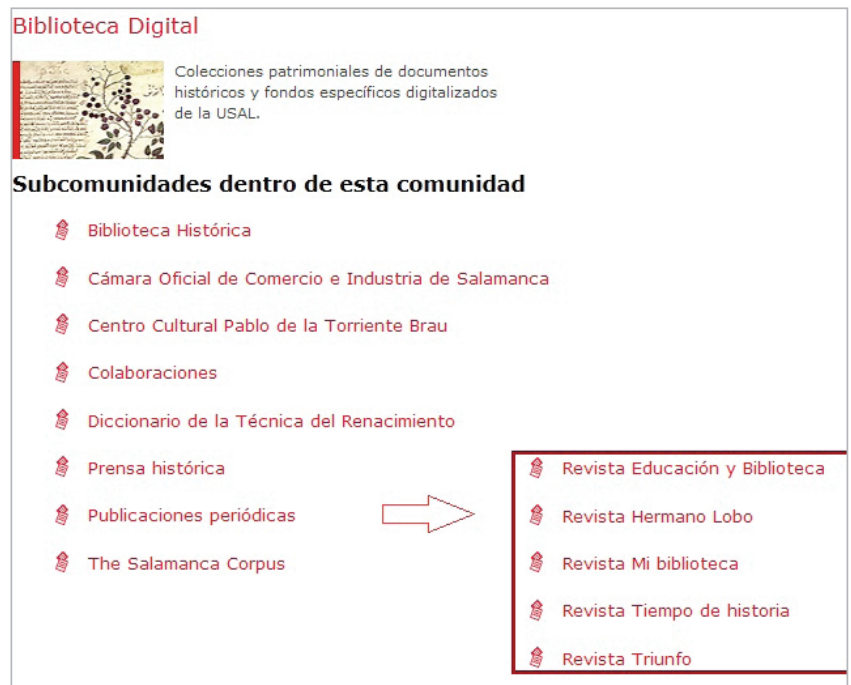

Imagen 8. Estructura de la Biblioteca digital de Gredos

Dialnet en ficheros RIS (formato de etiquetas estándar desarrollado por Research Information Systems, Inc., que permite el intercambio de datos a los programas de gestión bibliográfica). Dialnet puede exportar las citas en este formato, como se muestra en la imagen 2.

La imagen 3 muestra una ficha con etiquetado RIS de la descripción de un artículo de Educación y biblioteca en Dialnet.

5. Conversión automatizada de ficheros RIS a ficheros RDF (Resource description framework), que es un lenguaje para la representación de información sobre recursos en la Web. En el caso de Educación y biblioteca se trataba de hacer la conversión automática del formato RIS a RDF con etiquetas $D C Q$ (como se muestra en la imagen 4) mediante un programa informático propio, de forma que se pudieran importar los ficheros resultantes en Gredos.

\section{Tratamiento y carga de los objetos digitales}

Para el tratamiento de los objetos digitales se hicieron las siguientes tareas (imagen 5):

- desbloqueo de los pdfs de cada número proporcionados por la editorial; 
- digitalización de los números disponibles únicamente en papel; se crearon ficheros pdf de cada artículo, siguiendo los parámetros de digitalización y difusión web establecidos para el repositorio Gredos (imagen 5). Los pdfs tienen una resolución de 150 ppp (puntos por pulgada).

- Exportación de imágenes con nombres normalizados de los pdfs originales.

- Creación de miniaturas y asignación de una imagen para cada colección a partir de las portadas de los distintos números de la revista para importar en Gredos.

- Realización de OCR a todos los ficheros pdf.

Una vez finalizados estos procesos se procedió a la carga en el repositorio. La carga

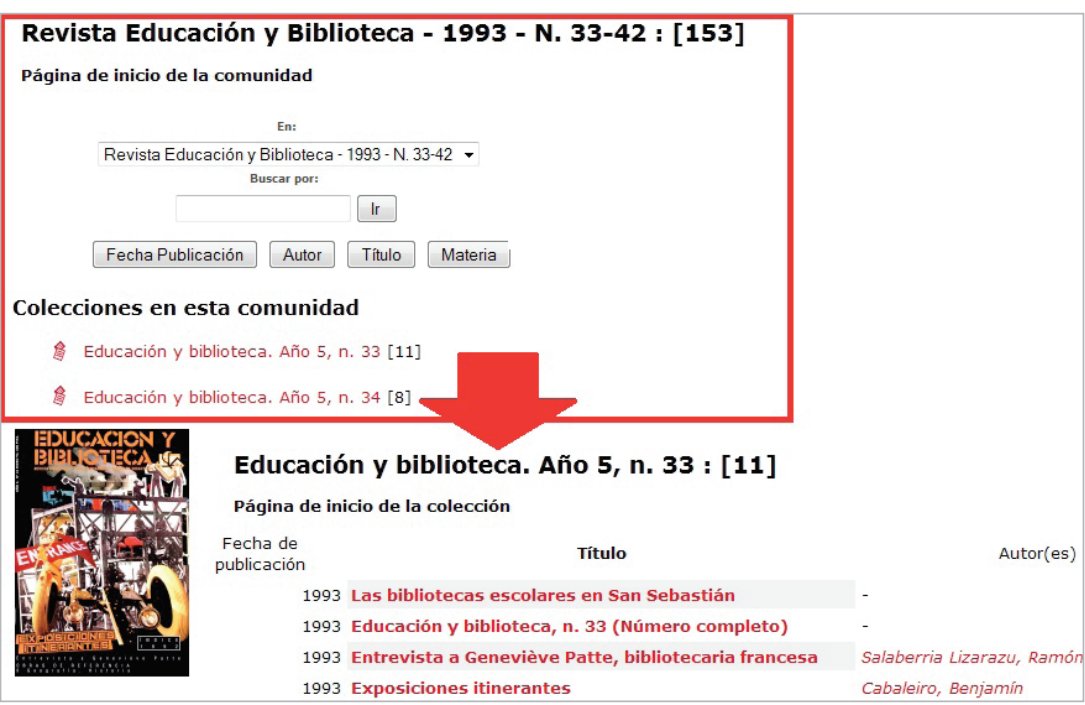

Imagen 9. Estructura "comunidad-subcomunidad-colección-ítem" masiva de la revista requirió crear previa-

mente la arquitectura necesaria (comunidades y colecciones). Una vez cargadas las colecciones faltaba la descripción de los números completos de la revista. El sistema de creación de ítems con el número completo no estaba automatizado, como en el caso de cada uno de los artículos, por lo que se crearon manualmente.

Un grupo de trabajo añadió palabras clave a cada artículo de la revista, tarea que aún sigue realizándose en el momento de publicar este trabajo.

\section{Educación y biblioteca en Gredos}

El repositorio Gredos se estructura en cuatro grandes secciones, atendiendo al tipo y procedencia de los fondos: Ar-

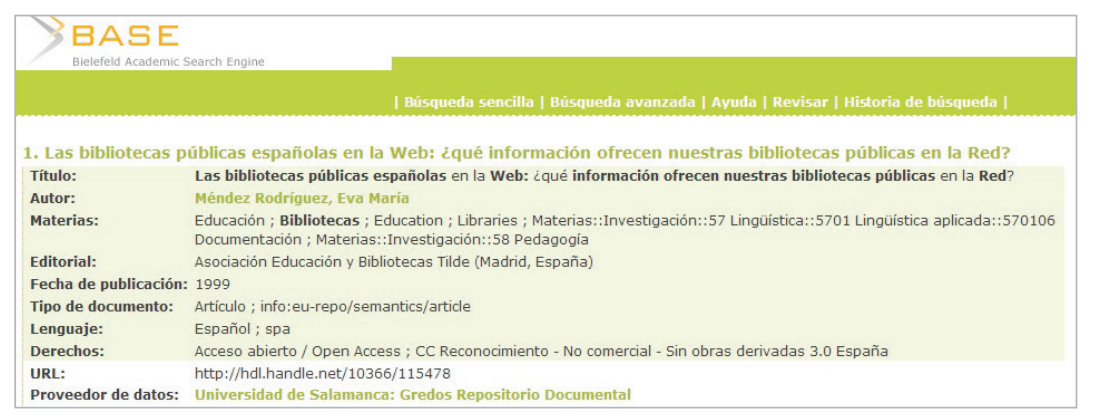

Imagen 10. Registro de EyB en Base

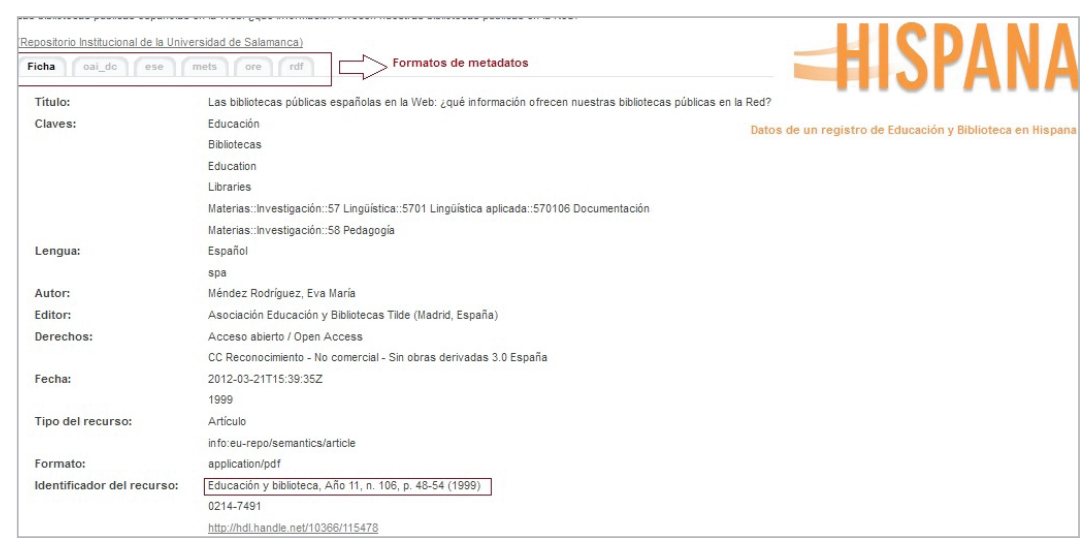

Imagen 11. Registro de EyB en Europeana chivo institucional, Biblioteca digital, Repositorio científico y Repositorio docente (imagen 7).

La sección Biblioteca digital alberga no sólo el fondo histórico patrimonial de la USAL sino también otras publicaciones periódicas fruto de los convenios realizados con instituciones ajenas: Triunfo, Tiempo de Historia, Hermano lobo (imagen 8).

Educación y biblioteca es una "comunidad" dentro de la sección Biblioteca digital, estructurada en subcomunidades correspondientes a cada uno de los años de publicación de la revista, y éstas en "colecciones" correspondientes a cada uno de los números. EyB consta de 23 subcomunidades (años 1989 a 2011) y 183 colecciones (números de la revista), con 2.466 ítems (registros o contribuciones) (imagen 9 ).

\section{Interoperabilidad y diseminación}

El éxito de los repositorios en acceso abierto se basa en la interoperabilidad, entendida como la capacidad para comunicar sistemas entre sí y transferir información de ida y vuelta en un formato utilizable. La interoperabilidad permite agregar contenidos, minar datos, crear nuevas herramientas y servicios y generar nuevo conocimiento del contenido de los repositorios.

En Gredos se han implementado esquemas de metadatos como ESE (Europeana semantic elements) y aplica directrices Driver. El citado protocolo OAI-PMH permite que los metadatos sean recolectados por agregadores como Hispana, Europeana, OAlster y BASE (Bielefeld academic search engi$n e)$, sin olvidar Google scholar (imágenes 10,11 y 12). 


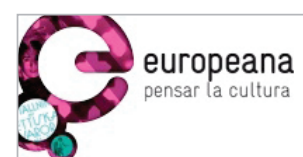

\section{Explora las colecciones cultura
Las bibliotecas públicas españolas en la Web}

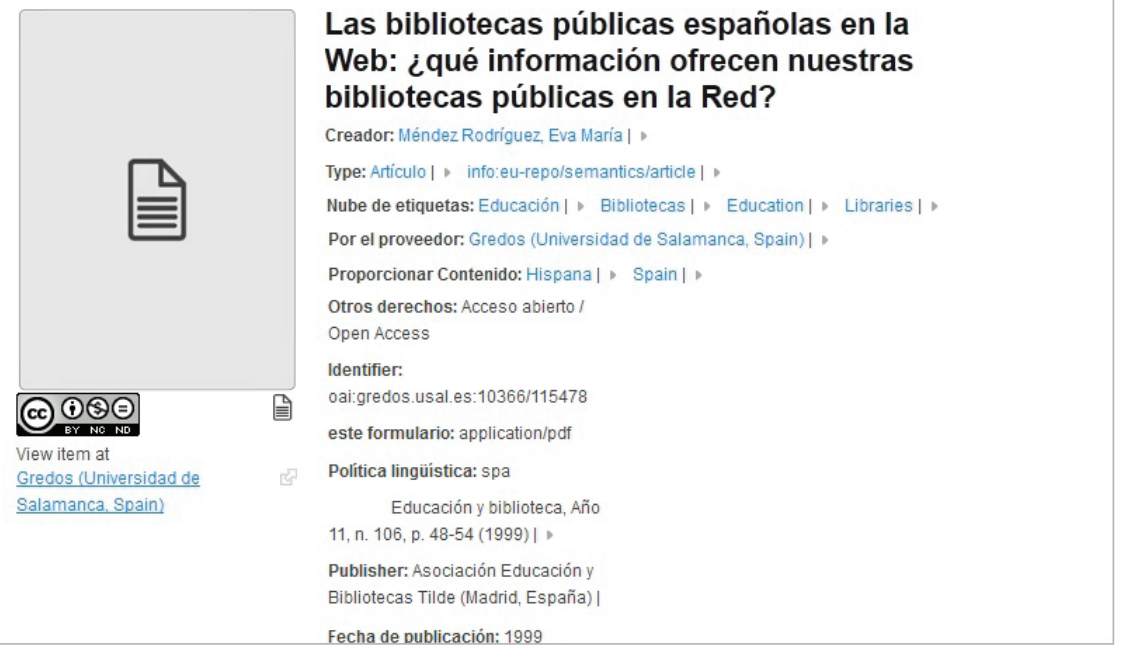

Imagen 12. Registro de EyB en Europeana
Dialnet

http://dialnet.unirioja.es

Driver

http://www.driver-repository.eu

DSpace

http://www.dspace.org

Dublin core metadata initiative

http://dublincore.org

Europeana

http://europeana.eu

Google académico

http://scholar.google.es

Gredos

http://gredos.usal.es

Hispana

http://hispana.mcu.es

$\mathrm{OAI}-\mathrm{PMH}$

http://www.openarchives.org/pmh

\section{Resultados e impacto previsto}

El objetivo principal del proyecto está cumplido, ya que se ha conseguido que las 2.466 contribuciones publicadas en Educación y biblioteca estén en acceso abierto, siguiendo estándares internacionales de descripción y de intercambio de metadatos.

El impacto o la influencia de Educación y biblioteca se recoge en diferentes trabajos sobre la investigación en biblioteconomía (Delgado-López-Cózar, 2007; Frías; Romero-Gómez, 1998; Salvador-Oliván; Lamarca-Langa; Arquero-Avilés, 2009; Torres-Salinas; Delgado-López-Cózar; Jiménez-Contreras, 2009). La evolución del número de sus citas se recoge de forma periódica en In-Recs, que ha analizado más de mil artículos de la revista. La previsión es que aumente el conocimiento de los artículos publicados en Educación y biblioteca, dado que ya se cumplen todas las condiciones para que de forma sencilla se acceda a sus contenidos.

La revista se debe reconocer como patrimonio del colectivo profesional, quien dispone de una fuente de referencia para conocer tanto la evolución profesional, como para estudiar el trabajo realizado por las diferentes bibliotecas que compartieron sus experiencias a través de la revista. Son de destacar sus números especiales sobre automatización, sistemas bibliotecarios, bibliotecas escolares, historia de la biblioteca en España, promoción de la lectura o web social, por ejemplo.

\section{Recursos}

\section{BASE}

http://www.base-search.net
OAI-ORE

http://www.openarchives.org/ore

OAlster

http://oaister.worldcat.org

RDF

$h t t p: / / w w w . w 3 . o r g / R D F$

\section{Bibliografía}

Delgado-López-Cózar, Emilio (2007). “Índice de impacto de las revistas españolas de biblioteconomía y documentación". Anuario ThinkEPI, v. 1, pp. 32-42.

Frías, José-Antonio; Romero-Gómez, Purificación (1998). “¿Quiénes son y qué citan los investigadores que publican en las revistas españolas de biblioteconomía y documentación?" Anales de documentación, v. 1, pp. 29-53.

http://revistas.um.es/analesdoc/article/view/3101/3071

Salvador-Oliván, José-Antonio; Lamarca-Langa, Genaro; Arquero-Avilés, Rosario (2009). "La percepción de la calidad y la utilización de revistas académicas por el personal docente e investigador del área de conocimiento de Biblioteconomía y Documentación". Documentación de las ciencias de la información, n. 32, pp. 193-206.

http://revistas.ucm.es/index.php/DCIN/article/view/ DCIN0909110193A

Torres-Salinas, Daniel; Delgado-López-Cózar, Emilio; Jiménez-Contreras, Evaristo (2009). "Redes de citación de las revistas españolas de Ciencias Sociales 1994-2006". Revista española de documentación científica, abr./jun., v. 32, n. 2, pp. 34-50.

http://eprints.rclis.org/13904

http://dx.doi.org/10.3989/redc.2009.2.686 